\title{
EL IMAGINARIO IDENTITARIO CUBANO EN LOS PRIMEROS VEINTE AÑOS DE LA REPÚBLICA (1902-1922)
}

Irina Pacheco-Valera

\section{RESUMEN}

El presente artículo versa sobre la construcción del imaginario identitario cultural cubano en los primeros veinte años de la República desde los diálogos de continuidad y discontinuidad con la Colonia. Las polémicas o contrapunteos que se dieron en torno a la temática de la negritud como clave identitaria desde las confluencias e interinfluencias con el entramado social constituyen la agenda temática que se potencia para sumarnos en los esfuerzos por repensar el misterio de lo cubano en la órbita del Caribe.

PALABRAS CLAVES: identitario, contrapunteo, cubano.

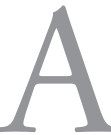
l abrazar el lente identitario cultural en los corrimientos de Cuba desde la construcción simbólica de la República, estamos abocados teórica y metodológicamente a ampliar el ojo social, que no se reduce sólo, por tanto, a la estructura clasista. Las diatribas identitarias atraviesan las marcas de la estratificación etnocultural y etnosocial que superan a la estratificación clasista. La construcción y deconstrucción de los grupos dominantes o hegemónicos y sus relaciones con los subalternos nos dan la atmósfera de los dispositivos de poder de la sociedad, vistos estos espacios no sólo desde los ejes del dominio político o económico, sino desde la hegemonía cultural e ideológica de los hombres y mujeres que conformaron el escenario cubano de cada tiempo histórico. Las bases identitarias de la República cruzan por los abordajes de estas relaciones de poder y los modos de sentir y expresarse mediante las propuestas ideoestéticas de los diversos grupos, sus producciones y consumos culturales en el itinerario de sus contrapunteos y polémicas culturales. 
El estudio de la República ha atravesado en el campo historiográfico cubano por momentos lánguidos en su cabal comprensión, pues como destacara el ensayista Fernando Martínez Heredia:

Han sido usuales dos errores en la comprensión de esta época, y no sólo de ella. Uno es creer que el conservadurismo cubano no existió más que como telón de fondo, o maldad que realza la virtud revolucionaria. El otro es eliminar las mediacione -que son esenciales en los hechos y por tanto para el conocimiento- existentes en cada etapa entre la realidad constituida por el consumo y la producción de ideas y las realidades económicas y políticas, y eliminar o ver muy simplistamente las acumulaciones históricas que porta cada dimensión de una sociedad dada. Estas prevenciones son imprescindibles para la comprensión de la lucha de ideas que se ventiló en la Cuba de los primeros ańos $20{ }^{1}$

Esas coordenadas nos permiten descifrar los elementos de continuidad y ruptura de cada etapa de la República, pues si bien el período histórico-cultural de Cuba marcado por la interacción de la vanguardia intelectual desde 1923 a 1958 constituye un momento decisorio en el complejo camino del alcance de la cubanía, la citada etapa es imposible analizarla sin tener en cuenta la configuración de las convergencias y divergencias con la etapa de 1880 a 1930, pues desde aquí germinaron los cimientos económicos, sociopolíticos y culturales de la conformación republicana y se vislumbraron las certidumbres e incertidumbres del cambio de siglo ${ }^{2}$. Los debates entre la herencia histórica del ideal decimonónico ilustrado de los proyectos reformistas y de los ideólo-

1 Fernando Martínez Heredia: El corrimiento hacia el rojo, Editorial Letras Cubanas, La Habana, Cuba, 2001, p. 166.

2 Véase: María del Carmen Barcia: "La sociabilidad de las capas populares en la conformación de una sociedad moderna. Cuba (1880-1930)", en Colectivo de Autores: Historia y memoria: sociedad, cultura y vida cotidiana en Cuba.1878-1917, [Prólogo de José Amador], Centro de Investigación y Desarrollo de la Cultura Cubana Juan Marinello- Programa de Estudios de América Latina y el Caribe. Instituto Internacional -Universidad de Michigan, La Habana, 2003. Además se debe revisar: Eduardo Torres Cuevas: En busca de la cubanidad, Tomo II, Editorial de Ciencias Sociales, La Habana, Cuba, 2006. 
gos del pensamiento independentista cubano enuncian una memoria histórico-cultural matizada por las epopeyas libertarias contra el dominio español, pero con una soberanía lastrada por la intervención norteamericana en nuestra Guerra de 1895, y por la posterior ocupación (1899-1902) que cerró su ciclo con la imposición de la Enmienda Platt, como apéndice de la Constitución de 1901. ${ }^{3}$ Desde ese momento, hasta la década del treinta del siglo XX, la hegemonía política, desde las operaciones del poder Ejecutivo y Legislativo, de los presidentes de la República, devino en la acción de los "generales y doctores". ${ }^{4}$

El entramado tiene una mismidad significante para el acumulado histórico de la nación, y es la reorganización de la dinámica socioclasista de los correlatos hegemónicos, pues el patriciado criollo rompe con su tradición y se desplaza hacia nuevos espacios de empoderamiento económico. Quizás uno de los agudos enfoques a este respecto lo ofreció la estudiosa cubana, Enma Álvarez Tabío, al puntualizar:

El patriciado cubano de la segunda mitad del siglo XIX, consciente de las trabas impuestas al desarrollo económico del país por las obsoletas estructuras coloniales españolas, asume el papel de la clase progresista dentro del orden económico de un capitalismo incipiente. Sin embargo, de la misma manera que los mecanismos económicos españoles estaban lastrados por la subsistencia del feudalismo, la burguesía cubana llevaba al pie el grillete de la esclavitud, en la que sustentaba el sistema económico. De esta manera se produce el curioso fenómeno de que esta clase social cuestione su propia estructura económica, cuestionamiento que había de manifestarse en el rechazo a la esclavitud y en la entrega a la causa de la independencia, único camino que libraría las fuerzas productivas de un nuevo sistema económico: el capitalismo. [... $]^{5}$

3 Eduardo Torres Cuevas: "Una reflexión; una incitación”, En busca de la cubanidad, Tomo II, Editorial de Ciencias Sociales, La Habana, Cuba, 2006, p. 301.

4 Véase la novela de Carlos Loveira: Generales y Doctores, Instituto del Libro, La Habana, Cuba, 1973.

5 Emma Álvarez Tabío Albo: Vida, mansión y muerte de la burguesía cubana. Editorial Letras Cubanas, La Habana, Cuba, 1989, pp.38-39, 44-45. 
Por su parte, el historiador Carlos del Toro, argumentó a su vez la reconfiguración de la alta burguesía cubana, desde las posiciones que esta tuvo en las carreras profesionales y en las disciplinas científicas o económicas, más que en las artes o en la literatura. Estas carreras especializadas se desarrollaban en su mayoría en el extranjero, además que la enseñanza privada-impartida por religiosos y laicos-resultó el medio fundamental de desarrollo cultural de esta clase. El bautizo, las bodas y los funerales constituyeron las ceremonias esenciales de los vínculos familiares y colectivos del grupo social. Como también profundizó Carlos del Toro:

Las instituciones sociales de la alta burguesía proclaman, en reglamentos y estatutos, el mantenerse independientes de cualquier tendencia política o partidista. Sin embargo, aquellas que contaron con un órgano de difusión-por ejemplo, el Havana Yacht Club (HYC), fundado en 1886-hicieron manifestaciones de inequívocas simpatías hacia los sucesos nacionales beneficiosos al grupo social nucleado en su seno. [...] La concepción extremista y sin matices [...] conduce a negar la existencia de una "clase alta trabajadora, realmente una clase de hombres prodigiosamente activos". Esto a su vez, no significa ignorar la presencia de una "clase ociosa" principalmente representada por el propietario o capitalista absentista, el cual es un sector de la alta burguesía. Durante la República neocolonial, las figuras más sobresalientes de la élite oligárquica doméstica no constituyeron precisamente una supuesta clase ociosa, pues laboraron de manera afanosa para el incremento de sus fortunas y ser triunfadores en la competencia con los rivales económicos. ${ }^{6}$

En los enjuiciamientos de la época, muchos veían el momento como "preparatorio" para enseñar a los cubanos hasta que ingresaran totalmente en la nación norteńa. El período se consideró propicio cuando en 1906 las pug-

6 Carlos del Toro: La alta burguesía cubana. 1920-1958, Editorial de Ciencias Sociales, La Habana, Cuba, 2003, pp. 108-109. 
nas políticas entre los grupos de poder político erosionaron el establecimiento institucional de nuevo estreno y propiciaron la segunda intervención norteamericana. La "crisis cívica” del cubano para activarse como sujeto movilizador demostró la imposibilidad para ser independientes desde los códigos axiológicos de la civilización norteamericana y de su tutelaje imperial. Pero esas proyecciones sociológicas de los cubanos debían buscarse en la construcción de la historia desde sus antecedentes coloniales.

En la historiografía cultural se recoge, tradicionalmente, que la etapa de 1899 a 1922, fue de frustración y desencanto republicano. ${ }^{7}$ Pero también, los primeros años republicanos enriquecerían nuestras cambiantes marcas identitarias, por un lado la huella cultural hispana y por otro, los diálogos con el modo de vida norteamericano. Más allá de intentar asumir patrones norteamericanos, se condicionó un camino de búsquedas, de encuentros y desencuentros entre ambas culturas, lo que patentiza la revitalización en cuanto a códigos de nación para ambos polos identitarios.

En los años de 1899 a 1922 se realizan estudios reveladores de indagación de nuestras raíces y críticas de los males republicanos, entre los que se destacaron los elaborados por personalidades como Regino Boti, José Manuel Poveda, Francisco José Castellanos, Bernardo G. Barros, José Antonio Ramos, José María Chacón y Calvo, Medardo Vitier, Dulce María Borrero, Carolina Poncet, Laura Mestre y Max Henríquez Ureña. Fernando Ortiz y Ramiro Guerra serían dos puntales en las búsquedas y preocupaciones de nuestros orígenes. Y en esa época, Enrique José Varona pronunció su conferencia "El imperialismo a la luz de la sociología” (1905).

La República que nace el 20 de Mayo de 1902, a la luz de sus paradojas, la podemos situar con una mirada a la efeméride, según asevera la profesora Ana Cairo, como "fecha gloriosa", al reflexionar así:

Se aspiraba a que la fiesta nacional del 20 de mayo desarrollara una tradición similar a la del diseño y atributos del 4 de julio en los Estados Unidos de América: un día de descanso laboral, de

7 Quizás uno de los más agudos análisis al respecto lo sintetizó el doctor Eduardo Torres-Cuevas, al pronunciar las posibilidades creativas que también brindó el estreno de República. Véase: Eduardo Torres- Cuevas: "Una reflexión; una incitación”, En busca de la cubanidad, Tomo II, Editorial de Ciencias Sociales, La Habana, Cuba, 2006, p. 303. 
convite familiar, de paseos, excursiones, fiestas y bailes públicos. Se le adicionó el de la apertura de temporada de modas, el del inicio del verano (para bañarse en las playas, irse de vacaciones, o cambiar el color del vestuario en las empleadas de comercios.

[...] Se transculturaron nuevos códigos con increíble celeridad y eficiencia. Los códigos de la imagen pública (como instrumento de la política y la cultura), las formas del consumo, la pasión por las novedades (de todo tipo) y las modas, la afición por el espectáculo con un ritmo dinámico, se fueron readecuando y estilizando hasta ser ingredientes de un modo de vida cubano para la cultura cubana del siglo XX. ${ }^{8}$

No debemos olvidar los pasos orientados a la difusión cultural por parte de determinadas instituciones sin apoyo de los gobiernos, sino por iniciativa privada. Uno de los esfuerzos más significativos lo llevó a cabo La Sociedad de Conferencias (1910-1915), creada por Jesús Castellanos y Max Henríquez Ureña. Sin vínculos oficiales, ellos propiciaron una institución verdaderamente cultural: dictaban sus conferencias y realizaban actividades culturales, históricas, con apoyo de obras musicales, en distintos salones, fundamentalmente en El Ateneo de La Habana. En sus predios, además de sus padres gestores, en esta sociedad participaron Enrique José Varona, Evelio Rodríguez Lendián, Miguel de Carrión, Juan Gualberto Gómez y Fernando Ortiz, entre otros.

En la música, tanto Guillermo Tomás (1868-1933) y Eduardo Sánchez de Fuentes (1874-1944) son los músicos más representativos del primer cuarto del siglo XX. Estéticamente considerados, puede decirse que ambos son el resultado de una continuidad del siglo XIX, después de la abortada soberanía. La labor de Tomás tuvo más resonancia en lo que se refiere a la creación de organismos musicales y a la divulgación de algunas partituras europeas desconocidas en Cuba (de Wagner, Berlioz, Debussy, entre otros). Músico de sentido sentimiento patriótico, ya para 1896 había dedicado un Canto de Guerra a los independentistas.

8 Ana Cairo Ballester: 20 de Mayo, ¿fecha gloriosa?, Editorial de Ciencias Sociales, La Habana, Cuba, 2002, p. 65-66. 
Eduardo Sánchez de Fuentes, con sus aciertos y limitaciones, es muy representativo de ese período de nuestra historia musical, inclusive por su sistemática oposición a los elementos estilísticos de la música negra, llegó a proclamar algo así como un "racismo estético". Discípulo de Cervantes, a los dieciséis años compuso la célebre habanera Tú. En 1894, presentó una ópera: Yurumí, donde desde ese momento presenta sus justificaciones para probar los orígenes de nuestra música desde lo aborigen. Escribió otras óperas, entre éstas La Dolorosa. Además del aporte que brindó con sus canciones, que poseen un carácter antológico.

Son momentos de fertilidad en lo concerniente a la música popular y trovadoresca, con figuras como Sindo Garay (1866-1968), Moisés Simons (1890-1945), Manuel Corona (1880-1950), Rafael Gómez (1888-1971), Alberto Villalón (1882-1955), Rosendo Ruiz (1885-1983), y de legítima música popular que se expresó en los intérpretes de orquestas, conjuntos, septetos, tríos y solistas. Proliferó la fundación de bandas de música. Por ejemplo: en el año 1899 se fundó la Banda Municipal de La Habana, siendo su primer director Guillermo Tomás, y después el maestro Gonzalo Roig. La Banda de la Marina de Guerra, estuvo dirigida por Armando Romeu, la Banda de la Policía, tenía al frente a Alberto Romaguera; y Antonio Fernández Nodarse, era el director de la Banda del Estado Mayor del Ejército.

La difusión de las publicaciones periódicas musicales también es destacada en los albores de la República. No podemos olvidar, que en 1884, Anselmo López fundó El Mundo Artístico, revista musical que alcanzó renombre y entre cuyos colaboradores figuraron nombres ilustres, como los de Gabriel M. Valverde, crítico musical que con el seudónimo de Edgardo figuraba como director de dicha revista; Nicolás Ruiz Espadero, Serafín Ramírez, Nicolás Azcárate, Antonio Peña, Ignacio Cervantes, Rafael Montoro, Fernando Arizti, Enrique José Varona, Pablo Desvernine, Ramón Suárez Inclán, Gaspar Villate, Miguel González Gómez, Tomás Ruiz, Rafael Díaz Albertini, y Rafael Salcedo, prestigioso profesor de Santiago de Cuba.

Para 1899, el crítico y comentador Serafín Ramírez inicia la publicación de una revista denominada Gaceta Musical. Se publicó durante cuatro años consecutivos, y desapareció en 1902. La revista quincenal Cuba Musical, la

9 Véase Serafín Ramírez: La Habana artistica, La Habana, 1891. 
cual no fue, en rigor, una revista exclusivamente dedicada a los asuntos musicales, más bien estaba dedicada a teatros y bellas artes, y en su primera edición se planteaba: "Podría entenderse que Cuba Musical habrá de ocuparse exclusivamente en asuntos musicales o que con el divino arte se relacionen. Y no es así, porque aún concediendo nuestra revista especial atención a la música, sus columnas se ufanarán rindiendo culto a la amena literatura y al arte en todas sus manifestaciones" ${ }^{10}$; Cuba Musical fue fundada por el maestro Hubert de Blanck en 1901, y en ella colaboraron: Ubago, Baralt, Blanck, Muñoz Bustamante, Joaquín Nin, de ahí que esta revista se erigiera -según criterios de José Raventós-:" [...] la primera publicación cubana de este género en el siglo XX"11 Porque tiempo después recesó dicha publicación, siendo continuada a partir del 1ro. de septiembre del año 1903 por José Marín Varona, con el mismo nombre, hasta mediados de 1905, y su último número apareció el 15 de junio del citado año, en que dejó de publicarse.

Fechado el 1 ro. de febrero de 1908 apareció el primer número de Bellas Artes, revista artística ilustrada, cuyo director y fundador, fue el maestro Guillermo Tomás. La revista Bellas Artes se destacó por ser una de las mejores revistas musicales de su etapa, con una lujosa impresión, con grabados y artículos de gran interés donde figuraron como redactores Rafael Pastor, Fernando Carnicer, José Manuel Fuentevilla, Miguel Ángel Mendoza, Felipe Pedrell, Henry T. Finck, Joaquín Nin, Gustavo Saenger y Rafael Blanco. Bellas Artes dejó de publicarse a los seis meses de su fundación. Un año más tarde, en 1909, Anselmo López, funda también el Boletín Musical de La Habana, en el cual figuraba como director propietario, y tuvo como jefe de redacción a Miguel González Gómez. Esta publicación no fue propiamente un periódico musical y sí de anuncio y propaganda, del almacén de pianos del maestro Anselmo López, de igual manera que la revista de la Sociedad Filarmónica, fundada por Joaquín Nin y sólo duró el año 1910. Así, como la revista Marín Varona, boletín mensual del Conservatorio Masriera, que sólo publicó un número en $1916 .{ }^{12}$

10 José Cosculluela: Progresos de la prensa musical en Cuba. Biblioteca Música, La Habana, Imprenta de la Revista Música, 1916, p. 10.

11 José Raventós: “La Música en Cuba desde 1902 a 1952”, en revista Carteles, no. 20, Mayo 18 de 1952, p. 90.

12 Véase José Cosculluela: Ob. Cit; José Raventós: Ob. Cit; José Ardévol: Introducción a Cuba: La Música, Instituto del Libro, La Habana, Cuba, 1969. 
Trascendental fue la labor de divulgación musical realizada por el maestro Hubert de Blanck, en el periódico La Discusión; Isidro Corzo, en El Triunfo; el maestro Rafael Pastor, en el Diario de la Marina; Max Henríquez Ureña, en distintas publicaciones; Tomás Jústiz y Miguel González Gómez, en el Heraldo de Cuba y La Nación; Julio Laurent Pagés, en El Sol, con una sección diaria dedicada a los músicos y José Cosculluela, en El Día y La Noche.

La República, de manera controversial, además, expresó la herencia de la supervivencia de la colonia en las estructuras económicas, jurídicas, políticas, administrativas y culturales del naciente estado nacional formal, el cual a su vez estaba distorsionado en su esencia por la dependencia al modelo modernizador norteamericano y que se insertaba en un imaginario social que buscaba las vías para la legitimación republicana desde las estrategias de dominio de una nueva élite política republicana y dirigente, proveniente de un mambisado degradado y corrompido, que ejerció un dominio político en los primeros treinta ańos de la República, hasta Gerardo Machado (1925-1933). Éste constituyó el último acto de esa depauperación y del añejo estilo de hegemonía política, que reorganiza los viejos espacios y se expandió a otras novedades organizativas como "liceos, escuelas, iglesias, bibliotecas, asociaciones deportivas o recreativas. La política, hasta la década del treinta, tendrá dos rasgos distintivos: el constante temor a una nueva ocupación norteamericana y la sucesión de los veteranos de las guerras decimonónicas en la escena política de la nación". ${ }^{13}$

Según los estudios del historiador Emilio Roig de Leuchsenring, en los veinte años republicanos estuvo presente "la colonia superviva" ${ }^{4}$. Esta expresión le dio título a un texto publicado por Emilio Roig, donde profundiza en la desunión, desorganización, y en el falso cooperativismo. Destaca la despreocupación por parte de los politiqueros de la época por nuestras

13 María del Pilar Díaz Castañón: Ideología y Revolución. Cuba, 1959-1962, Editorial de Ciencias Sociales, La Habana, Cuba, 2001, p. 99-100.

14 Véase Emilio Roig de Leuchsenring: La colonia superviva. Conferencia leída el 11 de abril de 1924 en la Séptima Reunión Anual de la Sociedad Cubana de Derecho Internacional. Imprenta Siglo XX, 1925. Sobre los pendientes de la Colonia en la República, véase también a Oscar Loyola Vega: "Problemas históricos vigentes", en Eduardo Torres Cuevas y Oscar Loyola Vega: Historia de Cuba. 1492-1898. Formación y liberación de la nación, Editorial Pueblo y Educación, La Habana, Cuba, 2001, p. 398. 
instituciones oficiales de enseñanza. Especial mención hace de la tragedia del guajiro, y a la pérdida de la tierra y la economía nacionales, así como de las quebraduras del poder judicial producto de la haraganería, la cobardía y la guataquería de magistrados y jueces. Se detiene en un fenómeno neurálgico en nuestra construcción identitaria que es el fenómeno de la discriminación racial. El debate racial y su ordenamiento están sumergidos en las encrucijadas de la cubanidad.

Cruciales son los análisis sobre en la diversidad contenida en los sectores, grupos y clases de los negros y mestizos, pues estos no constituyeron una masa homogénea. ${ }^{15} \mathrm{En}$ el acumulado histórico-cultural que le aportó la Colonia a la República, se pueden deslindar con claridad las posiciones diversas a través de las construcciones identitarias del poder, donde hay que tener presentes a la "pequeña burguesía de color" la cual reprodujo los patrones hegemónicos burgueses de las clases y sectores blancos. Un ejemplo de ello, en los tiempos coloniales, lo constituyeron los batallones de pardos y morenos, así como capataces de muelles, músicos y hábiles artesanos que desempeñaron disímiles oficios. ${ }^{16}$ De ahí que el estudioso Pedro Deschamps Chapeaux pronunciara:

La influencia del sistema esclavista alcanzaba por igual a todas las capas de la población. El blanco de escala inferior y el artesano pardo o moreno, libres, estaban en paridad de derechos con las denominadas clases superiores, para la adquisición de esclavos, aunque la condición de amo, tanto de uno como de otro, no mejoraba su posición social. El blanco de escasos recursos continuaba siendo catalogado como "hombre blanco de estado llano", "blanco de baja esfera", "blanco común", y el pardo o moreno, era discriminado a la par que su esclavo [...] Los pardos y morenos libres habían incorporado a su comportamiento habitual las normas impuestas por los colonialistas, a tal punto, que formaban parte también del mercado de esclavistas, sin que

15 Véase a María del Carmen Barcia: Ob. Cit., p. 276.

16 Véase Pedro Deschamps Chapeaux y Juan Pérez de la Riva: Contribución a la historia de la gente sin historia, Editorial de Ciencias Sociales, La Habana, Cuba, 1974. 
ello le permitiese traspasar las barreras sociales de un sistema en el cual el origen y el color de la piel eran dimensiones jerárquicas. ${ }^{17}$

En la última década de la esclavitud en Cuba se aunaron los contenidos desesperados de un sistema en quiebra, sus injusticas más marcadas con la gestualidad de sujetos en transición: los esclavos que se convertían en libertos; los esclavistas que se tornaban en patronos. Los comportamientos e identidades de un mundo post-esclavista se conformaron dentro de la descomposición de la esclavitud. Compartieron las marcas del imaginario esclavista con los rubros de trabajo libre, libertad personal y dignidad humana que definían el imaginario abolicionista. En medio de esa hibridez se establecieron patrones combinados de conducta e identidad: el paternalismo como guía para la gran mayoría de las relaciones personales y políticas; la sospecha velada respecto al mundo del trabajo y a todo lo que supusiera a márgenes, como por ejemplo, las mujeres y los libertos. Las estrategias de vigilancia e intervención se renovaron en la medida en que se proponía una nueva normalización con el fin del esclavismo. Ante la abolición, muchos propietarios y autoridades desplazaron su mirada hacia nuevas formas de control del trabajo y la disciplina. Michel Foucault, en su análisis sobre el nacimiento de la prisión moderna, destacó el surgimiento de una cultura de la vigilancia.¿Pero qué papel juega el cuerpo en estas nuevas reglamentaciones? Para Foucault, el cuerpo juega el papel primordial:

[...] el cuerpo está también directamente inmerso en un campo político; las relaciones de poder operan en él como sobre una presa inmediata; lo cercan, lo marcan, lo doman, lo someten a suplicio, lo fuerzan a unos trabajos, lo obligan a unas ceremonias, exigen de él unos signos. Este cerco político del cuerpo va unido, de acuerdo con unas relaciones complejas y recíprocas, a

17 Pedro Deschamps Chapeaux y Juan Pérez de la Riva: Contribución a la historia de la gente sin historia, Editorial de Ciencias Sociales, La Habana, Cuba, 1974, p. 49-50. Profundizar en el papel de la burguesía esclavista en: María del Carmen Barcia: Burguesía esclavista y abolición, Editorial de Ciencias Sociales, La Habana, Cuba, 1987. Así como, es de imprescindible, el estudio de Manuel Moreno Fraginals: “Azúcar, esclavos y revolución (1790-1868)”, en revista Casa de las Américas, no. 50, septiembre-octubre, La Habana, Cuba, 1968. 
la utilización económica del cuerpo; el cuerpo, en buena parte, está imbuido de relaciones de poder y de dominación, como fuerza de producción; pero en cambio, su constitución como fuerza de trabajo sólo es posible si se halla prendido en un sistema de sujeción [...] El cuerpo sólo se convierte en fuerza útil cuando es a la vez cuerpo productivo y cuerpo sometido. ${ }^{18}$

Los castigos jurídicos y lingüísticos que aprisionaron a los esclavos no fueron indescifrables. Conocemos de las resistencias individuales y colectivas que tomaron un universo de expresiones: cimarronaje, suicidios, sabotajes, mutilaciones y rebeliones. ${ }^{19}$

En 1899, cuando España terminó su posición colonial en el Caribe, una gama de posiciones sobre lo cubano y la nación cubrieron el archipiélago. Las polémicas sobre la creación de la República y la novedad cubana no versaban sólo en las materias de propiedad o reclamos institucionales, pues la confrontación de cuanto "racialmente incluyente e igualitaria debía ser la Cuba postcolonial" 20 atravesaban el debate.

Las propuestas y los espacios de los diversos grupos, sectores y clases sociales, aún estaban en el camino de las indeterminaciones para el año 1899. En ese juego epocal, interactuaban, de una parte, el Ejército Libertador, con un tradicional arraigo dentro del imaginario social y con una formación ideológica basada en la igualdad racial. Pero los móviles de los dispositivos de poder,

18 Michel Foucault: Vigilar y castigar, Nacimiento de la prisión, México: Siglo XXI, 1988, pp.32-33. Véase citado por Silvia Álvarez Curbelo: Un pais del porvenir, el afán de modernidad en Puerto Rico (siglo XIX), Ediciones Callejón, San Juan, Puerto Rico, 2001, p. 98-99.

19 Véase: José Luciano Franco: Los palenques de los negros cimarrones, La Habana, Editado por el Departamento de Orientación Revolucionaria del Comité Central del Partido Comunista de Cuba, La Habana, Cuba, 1973. Pedro Deschamps Chapeaux: Los cimarrones urbanos, Editorial de Ciencias Sociales, La Habana, 1983. Gabino La Rosa Corzo: Los cimarrones de Cuba, Prólogo de Julio Le Riverand, Editorial de Ciencias Sociales, La Habana, Cuba, 1988. Rebeca Scott: La emancipación de los esclavos en Cuba. La transición al trabajo libre 18601899, Editorial Caminos, La Habana, Cuba, 2001. Ana Cairo: Bembé para cimarrones, Publicaciones Acuario, Centro Félix Varela, La Habana, Cuba, 2005.

20 Alejandro de la Fuente: $A$ nation for all, The University of North Carolina Press, 2000. Véase la versión espańola del mismo libro: Una nación para todos: raza, desigualdad y politica en Cuba, 1900-2000, Editorial Colibrí, Madrid, España, 2001, p. 43. 
en el nuevo orden, no los tenía el Ejército Libertador, sino que fueron desplazadas de manera paulatina por las fuerzas de la intervención norteamericana primero (1898), y después se asientan en la etapa de ocupación militar (18991902) con el ejército norteamericano. Las fórmulas de dominación del archipiélago, iban con declaratorias sobre la composición racial de la población. En el posicionamiento social, las autoridades norteamericanas establecieron correlatos con las élites tradicionales cubanas, pues ambas partes estaban esperanzadas en la repartición de propiedades y privilegios. Los grupos, sectores y clases altas, con un pensamiento heredero de la sacarocracia criolla de fines del siglo XVIII y XIX colonial, objetaron a los afrodescendientes de la Isla como parte del proyecto de nación y revisitaron los códigos del miedo a que la negritud llevara a cabo una revolución y estableciera una república. Cada posición buscaba sus marcos de legitimidad desde sus posturas polémicas. El modelo nacionalista de inclusión racial, era apoyado por los imaginarios populares subalternos sustentados en el proyecto martiano de una República "Con todos y para el bien de todos”, y en las personalidades patrióticas del mambisado negro y mulato, entre los que se encontraron los líderes: Antonio y José Maceo, Guillermón Moncada, Flor Crombet, Jesús Rabí, Quintín Banderas, Agustín Cebreco, Pedro Díaz, Jesús Rabí, Juan Eligio Ducasse, Prudencio Martínez, así como el caso de Juan Gualberto Gómez, que aunque no procedía de la oficialidad mambisa, su labor en la organización de la Guerra de 1895 en la Isla fue crucial, así como su papel como presidente del Directorio Central de Sociedades de la Raza de Color (1892-1894) ${ }^{21}$ y la fundación de la publicación de los periódicos La Fraternidad (1886-1889) y La Igualdad (1892-1894). Todos estos veteranos y pinos viejos afrocubanos de las gestas liberadoras del siglo XIX se debatieron entre los reclamos de visibilidad y las estrategias coloniales de borramiento y silencio. ${ }^{22}$

21 Véase Oilda Hevia: El Directorio Central de las sociedades negras de Cuba, Editorial de Ciencias Sociales, La Habana, Cuba, 1996.

22 Véase el interesante estudio sobre estas figuras realizado por Alejandro de la Fuente: $O b$. Cit. Además es vital, la consulta de Tomás Fernández Robaina: El negro en Cuba: apuntes para la historia de la discriminación en Cuba (1900-1958), Editorial de Ciencias Sociales, La Habana, Cuba, 1990. Véase también: Oilda Hevia Lanier: "Otra contribución a la historia de los negros sin historia”, en revista Debates Americanos, n. 4, julio-diciembre, 1997, La Habana, p. 77-89. 
Las proyecciones de la exclusión racial tenían el descanso en las teorías del darwinismo social esbozado en las polémicas sobre raza, pues no se empleaba el concepto de etnia. Desde esos presupuestos científicos y con los análisis biológicos se establecieron las diferencias del conglomerado humano entre razas superiores y razas inferiores y se establecen a los más aptos y más capaces, donde los negros estaban destinados a las clasificaciones de inferioridad y barbarie ante los proyectos civilizatorios modernos de los mecanismos sociopolíticos de los EE.UU. y las clases hegemónicas de Cuba. Con la tan solicitada cubanidad trazada desde los corrimientos del blanqueamiento de la población y con las socorridas claves culturales en Europa, el escenario era netamente desafiante para los afrocubanos. Dentro de las encrucijadas históricas en que estuvieron sumergidos los negros y mulatos estaban los dilemas de las políticas migratorias, que reclamaban la presencia de los braceros antillanos ante la expansión de nuestra producción azucarera durante y después de la Primera Guerra Mundial. En este ordenamiento, las prácticas discursivas dominantes sancionaron duramente a la inmigración antillana, pues la consideraron una amenaza para la higiene y la salud pública cubana.

Por otra parte, el discurso dominante se dio a la tarea de contener las manifestaciones religiosas de santería, pues eran vistas como actos de brujería, y también se enfrascaron en eliminar los bailes públicos de los negros y mulatos. Uno de los testimonios de lo susceptible de la sensibilidad cubana a todo lo relacionado con el folklore africano es el decreto que data del 26 de octubre de 1901 procedente de la Alcaldía Municipal, donde se prohibía la representación de la obra "Foros, Gallo y Náńigos" en el teatro Lara, por infringir la orden del 4 de abril de 1900 que proscribía el empleo de tambores de origen afro. Todas estas cosmovisiones de los afrocubanos eran supuestas como atraso y ejemplos de salvajismo, criminalidad y fetichismo, a la par que eran percibidos como episodios de degradación moral con índole diabólica. Además se fijaron prejuicios con la sexualidad afrocubana. Este estereotipo estuvo representado por un imaginario masculino bestial negro y con el violador negro de las mujeres blancas y en los símbolos femeninos de la negra carnal y mulata seductora. Pero no había representación del violador blanco de las mujeres negras, lo cual ocurría con bastante frecuencia.

El tejido hegemónico de los estereotipos raciales y culturales sobre los afrocubanos, eran parte de la bien concebida estrategia de desafricanización de 
la cultura cubana, lo cual fue muy discutido en el campo cultural de los intelectuales negros y mulatos, quienes se cuestionaron y enfrentaron todos estos argumentos colonizadores. Bajo los auspicios de la mal denominada "democracia racial" 23 , se encubrieron los impedimentos de la cultura dominante para brindarles espacios a los negros y mulatos en los terrenos sociales y políticos de poder. Aunque en muchos casos, los empleaban mediante campañas demagógicas de fraternidad racial cuando ocurrían las promociones electorales. Los funcionarios norteamericanos y las élites nacionales elaboraron una concepción muy propia y bastante efectiva ante las solicitudes de los derechos de ciudadanía y de organización política ante los interactivos puntos constitucionales de la naciente República. Como profundizó Aline Helg, en sus estudios: "la élite blanca de Cuba recurrió al mito de la existencia de la igualdad racial en la nación con el fin de justificar el orden social que existía. En general, los mitos latinoamericanos de igualdad racial crearon imágenes de una esclavitud suave, promoción del mulato (no del negro). Ausencia de segregación legal, y promiscuidad racial; mitos que transformaron a los negros en receptores pasivos de la generosidad blanca”. ${ }^{24}$

Las fuerzas que actuaron en las elecciones de 1901, para la selección entre los candidatos propuestos, estaban en su mayoría a favor de Estrada Palma, y trataron por todos los medios de evitar el triunfo de la tendencia independentista representada por Bartolomé Masó, pues este contaba con el respaldo popular, de una base negra y mulata.

Al ocupar la presidencia Tomás Estrada Palma (1902-1906), la división y segregación racial aumentó, con su política discriminatoria, pues la opinión pública no le perdonó jamás haber tenido una actitud tan mezquina con el General Quintín Banderas, al ofrecerle cinco pesos y un nombramiento de cartero como premio de sus servicios a la nación. Según precisó en su acuciosa investigación, Tomás Fernández Robaina: "El estado de subdesarrollo sociocultural en que se vio sumido nuestro país, y en particular el negro, aún más durante los años de la intervención norteamericana, lo vamos a palpar claramente por las referencias sobre esta etapa en un acto que se efectuó el 29

23 Véase Alejandro de la Fuente: Ob. Cit., p. 47

24 Aline Helg: Lo que nos corresponde: La lucha de los negros y mulatos por la igualdad en Cuba. 1886-1912, Ediciones Imagen Contemporánea, La Habana, Cuba, 2000, p. 8. 
de junio de 1902, en el Teatro Albizu, organizado por el Comité de Veteranos y de Sociedades de la Raza de Color, agrupación que había surgido para defender los derechos de los veteranos negros y combatir la discriminación”. ${ }^{25}$

Este acto inició un camino de discusiones sobre la problemática del negro cubano, las cuales se esbozaron en la prensa de la época en publicaciones como: El Nuevo Criollo (1904-1906), semanario dirigido por Rafael Serra; El Puritano, donde se denunciaba la política discriminatoria de Estrada Palma y se solicitaba la atención a los problemas de la población negra.

Ante la incongruencia del gobierno de Estrada Palma, mediante las solicitudes de intervención norteamericana en la isla para socavar la revuelta liberal de la llamada Guerrita de Agosto, establecida contra la reelección de éste como Presidente de la República. La intervención norteamericana se llevó a efecto, según hizo constar Roosevelt, por las amenazas que venían sobre las propiedades norteamericanas. Esta intervención, desde luego, terminó por sujetar los destinos del país a la política norteamericana. El historiador Jorge Ibarra destaca como:

En la opinión de Taft, la insurrección liberal de 1906 se había producido porque los cubanos no se interesaban en el dinero, sino en la política, y era su opinión que los dirigentes políticos cubanos debían interesarse en los negocios, participar en la economía del país e invertir el dinero que tuviesen, o convertirse en ejecutivos de las empresas norteamericanas, para que pudiesen conciliar los intereses políticos con los intereses económicos de los monopolios [...] Este proceso político de integración de los grupos políticos con la economía del país, empieza, precisamente, a partir de la intervención de 1906 [...] Aspiraban a convertirse en capital burocrático, político, para luego pasar a ser propietarios de bienes azucareros o de capitales agrarios. Se intentaba crear una clase política que integrara plenamente a las necesidades económicas de los grandes dueños de ingenios y de los monopolios. ${ }^{26}$

25 Tomás Fernández Robaina: Ob. Cit, p. 38-39.

26 Jorge Ibarra, Manuel Moreno Fraginals y Oscar Pino Santos: "Historiografía y Revolución" (mesa redonda), en revista Casa de las Américas, La Habana, no. 9, noviembre de 1968-febrero de 1969, p. 108. 
Estrada Palma se decidió a renunciar el 28 de septiembre de 1906, y acto seguido los marines norteamericanos con William Taft, declararon la segunda ocupación norteamericana, cedida para su cumplimiento a Charles Magoon (1906-1909). Con una muy bien diseñada política de divide y vencerás, este gobernador norteamericano se estableció, apoyado a su vez en los resortes de la corruptela político-administrativa de los políticos; basados en los gastos de los planes de Obras Públicas y en el empleo de la botella en las gestiones de posesión de cargos y puestos administrativos.

Los negros y mulatos, por su parte, para esta etapa ganaban en organicidad desde un rico espíritu asociativo que le ofrecía movilidad a los grupos subalternos populares en la dinámica de la sociedad civil. Una de las figuras más destacadas del movimiento negro del momento lo fue Evaristo Estenoz con su propaganda para la creación de una organización que representara a los negros en sus demandas. Por como señala el investigador Tomás Fernández Robaina, la constitución de la Asociación Independiente de Color $^{27}$, es ejemplo del trabajo de integración que se estaba llevando a cabo entre los sectores negros y mulatos. El Partido de los Independientes de Color había surgido en 1908, con el periódico Previsión (1908-1912) como su órgano vocero. El programa de los Independientes de Color iba más allá de la temática racial, para establecer vías de lucha social. ${ }^{28}$ De ahí las desconfianzas de los partidos Liberal y Conservador ante los espacios políticos que podían ocupar los negros en los comicios de 1908. Por lo que la declaratoria de Martín Morúa Delgado, con su Enmienda que impedía la creación de organizaciones políticas de un mismo grupo racial, fue aprobada por el Congreso de la República, para contener la fuerza de los Independientes de Color. Sus reclamos mediante un levantamiento armado en mayo de 1912, en pro de la derogación de la Enmienda Morúa, insertó a los Independientes de Color, en las expresiones tradicionales de la mismidad de los partidos políticos de la República, pues de

27 Véase Tomás Fernández Robaina: Ob. Cit., pp. 60-67. Además es puntual revisar: compilación e introducción de María del Pilar Díaz Castañón: Éditos inéditos, documentos olvidados de la historia de Cuba, Editorial de Ciencias Sociales, La Habana, Cuba, 2005. Porque en el referido texto se compila un trabajo muy interesante sobre el conflicto racial y los Independientes de Color, titulado: Pedro Alexander Cubas: "Posición de los parlamentarios cubanos negros y mulatos ante los sucesos de 1912”, p. 19-38. 
esta manera le solicitaban al presidente José Miguel Gómez (1909-1913) un lugar de representatividad en la vida política de su gobierno y manifestaban su desconcierto ante la omisión a que estaban siendo sometidos.

La aplicación de la "violencia oficial" 29 contra los negros, constituyó una característica del caso cubano colonial y republicano. Y más aún el calificativo de "protesta racista" fue entonces, y ha sido después, una patraña conscientemente urdida; primero, para avivar su aplastamiento, y segundo, para impedir en lo porvenir toda acción defensiva, reclamadora de derechos para la ciudadanía negra de nuestro país" ${ }^{30}$. El itinerario de esta exclusión revisitó las prácticas articulatorias coloniales desde los tiempos de la Sublevación de Aponte (1812) y de la Conspiración de la Escalera (1844), con la masacre a que fueron sometidos los Independientes de Color ${ }^{31}$ a partir de 1912 y la escalada de linchamientos sobre negros y mulatos hasta 1919. Con esto José Miguel Gómez se olvidaba de los intercambios que tuvo con sus principales dirigentes. Pero unos de los signos identitarios más controversiales en esta conmoción social y política son los desplazamientos de los dispositivos del poder, de los grupos hegemónicos de los sectores y las clases privilegiadas, donde no podemos desconocer a la aristocracia negra y mulata, los cuales reprodujeron los códigos identitarios de dominación blanca, al separarse de esta rebelión y del resto de su conglomerado étnico y no aprobar sus posiciones. Según indagó el investigador Pedro Alexander Cubas, para el 1ro. de junio de 1912 se reunió un grupo de parlamentarios negros y mulatos, para expresar sus criterios a través de una proclama titulada: "A Nuestro Pueblo". El citado documento fue firmado por Generoso Campos Marquetti y Luis Valdés Carrero (representantes por La Habana), Ramiro Cuesta y Juan Felipe Risquet (representantes por Matanzas), Manuel de Jesús Delgado y Hermenegildo Ponvert D'Lisle (representantes por Santa Clara), Nicolás Guillén (senador por Camagüey), Francisco Audivert, Alberto Castellanos, Agustín Cebreco y Lino D'Ou (representantes por Oriente). En el material esbozaron que no estaban de acuerdo con el levantamiento de los Independientes de Color, y del peligro que representaban estas acciones para el futuro de la nación:

\footnotetext{
29 Véase para profundizar en la temática a Aline Helg: Ob. Cit., p. 7.

30 Serafín Portuondo Linares: Los Independientes de Color, Editorial Librería Selecta, La Habana, Cuba, 1950, p. 209.

31 Véase Silvio Castro Fernández: La masacre de los Independientes de Color en 1912, Editorial de Ciencias Sociales, La Habana, Cuba, 2008, (Segunda edición).
} 
A nosotros hombres procedentes de la raza de color, nos importa formular enérgicamente nuestra reprobación al acto realizado por los "independientes de color"; y a la par, insistimos en demostrar su falta de justificación, precisamente porque es necesario evitar, en bien de la Patria, en bien de todos los moradores, lo mismo blanco que negros, que se engendre una lamentable confusión, por la torpe actitud de algunos extraviados. En ese orden de ideas, queremos declarar: primero, que aquí no está planteado un problema de raza; esto es, que no ha surgido un antagonismo entre los intereses de los blancos y de los negros cubanos; que no se ha atentado por los blancos a ningún derecho de los negros, y que no están los negros animados de ningún sentimiento de hostilidad hacia los blancos; segundo, que si en hora infausta para todos, se hubiese negado al negro cubano sus derechos, por nuestros antecedentes y por nuestro propio honor, nadie se nos hubiese adelantado en la hora de reivindicarlos, como lo hicimos muchos de nosotros cuando estuvieron negados en los tiempos coloniales; y tercero, que si así como es deber nuestro condenar el alzamiento de los Independientes de Color, permaneciendo fieles a la vieja y santa doctrina de la fraternidad entre las dos razas cubanas, también se impone a nuestros hermanos blancos la obligación de mantener su noble fidelidad a dicha doctrina, cuidando de no confundir a una ínfima minoría con la inmensa totalidad de la raza de color, y de no pronunciar palabras ni esbozar un gesto que den pábulo, hoy al recelo, mañana a la discordia entre nosotros. ${ }^{32}$

Las pautas de la rebelión estimularon a los "cubanos de color" a escoger los paradigmas de "civilización" en un lugar preponderante, atendiendo a los criterios de la élite blanca enfatizados en la atención a los problemas

32 "A nuestro pueblo", en Pedro Alexander Cubas: "Posición de los parlamentarios cubanos negros y mulatos ante los sucesos de 1912", pp. 34-35, en compilación e introducción de María del Pilar Díaz Castañón: Éditos inéditos, documentos olvidados de la historia de Cuba, Editorial de Ciencias Sociales, La Habana, Cuba, 2005. 
educacionales y culturales para llegar a ser plenos ciudadanos, por encima de los problemas de control económico de la hegemonía blanca y sobre los presupuestos de "conciencia de clase", lo cual potenció las divisiones entre los cubanos negros y mulatos.

En los años posteriores a 1912, la raza y la nación continuaron en las preocupaciones identitarias de los cubanos. Para 1919, en el período presidencial de Mario García Menocal (1913-1921), las intensas polémicas sobre la problemática revelaron el escenario marcado por los postulados de "civilización" y "barbarie". A partir de marzo de 1919, se señaló el comienzo de una amenaza de brujería, que terminaría con la muerte de ocho negros en Matanzas y el linchamiento de uno en Regla, acusados de secuestro, asesinato ritual y canibalismo de niños blancos. La prensa de la época anunciaba estos crímenes. ${ }^{33}$ Desde los mecanismos de la oficialidad, la policía se encargó de reprimir mediante el uso de los linchamientos a todo lo proveniente de los afrocubanos, y se estableció una triada entre la brujería, la barbarie y lo negro.

Los negros y mulatos en pos de radicalizar sus planteamientos crearon un contradiscurso, que reivindicaba su historia desde los tiempos ancestrales de la esclavitud. En ese espacio interactuaron los miembros del recién creado Club Atenas ${ }^{34}$, los cuales eran representantes de la élite negra y mulata. Ellos proclamaron una declaración cargada de una protesta cívica y se hicieron eco del proyecto de nación moderna ${ }^{34}$. Su manifiesto establecía una espinosa concepción de identidad, pues aunque situaban sus orígenes en un núcleo de personas de ascendencia africana, en posición similar al manifiesto de los negros parlamentarios de 1912, rechazan la identidad unitaria homogénea de los miembros de la "raza de color". Es decir, establecieron las diferenciaciones de clases y sectores y destacaban su confianza en los ciudadanos blancos, a la par que declararon la existencia de los "negros civilizados", gracias a la instrucción y la cultura. ${ }^{35}$

En la apertura del año 1924, a pocos años del movimiento afrocubano, la administración de Alfredo Zayas (1921-1925) dictó leyes que prohibían toda reunión de los negros y mulatos que comprendiera toques de tambor

33 Véase El Día, 23 de marzo de 1919; El Día, 22 y 25 de abril de 1919; El Día, 24 y 28 de junio de 1919.

34 Véase Club Atenas. Los partidos politicos y la Asamblea Constituyente. Asociación Nacional de Cultura y Afirmación Cubana, La Habana, 1939 [folleto].

35

Véase Alejandro de la Fuente: Ob. Cit., p. 320. 
y bailes, así como se impidieron las ejecuciones de rumbas o ceremonias de la santería o de la secta abakuá, como de otras expresiones afrocubanas. La corrupción político-administrativa incentivó el capital burocrático con la acumulación de capitales por los funcionarios estatales, quienes a su vez se desplazaron en la dinámica socioclasista hacia posiciones meritorias dentro de la "alta burguesía cubana". ${ }^{36}$

El desencanto cubano toma expresión de repulsa total y de cuestionamiento en el espacio de dominio del zayismo, pero este proceso tuvo sus antecedentes al decir por Fernando Martínez Heredia:

[...] Pero fue precedido por un hecho histórico que suele olvidar o subvalorarse: se había creado un campo de conciencia y protesta entre los trabajadores organizados, expresado en las grandes huelgas de 1919 y los años siguientes y el ascenso de un sindicalismo de tendencia anticapitalista. La hegemonía burguesa se erosionó por múltiples vías: desgaste de la política liberal-conservadora y pérdida de credibilidad de sus mensajes, imposiciones norteamericanas más severas, ausencia de alternativas nacionales al previsible fin de la expansión de una economía brutalmente deforme, y ambiente internacional de crítica y de ritos al imperialismo. El 1923 de rebeldía universitaria debe ser comprendido en ese marco de protestas y erosiones, para entender su alcance y sus límites, su apariencia efímera y sus potencialidades. ${ }^{37}$

En el período de posesión del general Gerardo Machado (1925-1933) se puso en vigor un autoritarismo cada vez más represivo y se anunció el fin del bipartidismo y los resortes estratégicos del poder. El término de la dinastía de los "generales y doctores" (1933) estimuló también la movilidad social. Se establecieron nuevos horizontes que representan la fractura con los moldes de

36 Véase: "Manifiesto relativo a los sucesos ocurridos en Regla y Matanzas a consecuencia de las prácticas de brujería y canibalismo", Archivo Nacional de Cuba, Fondo Adquisiciones, caja 65, No. 4201, pero además publicado en El Día, 2 de agosto de 1919.

37 Véase Carlos del Toro: La alta burguesía cubana. 1920-1958, Editorial de Ciencias Sociales, La Habana, Cuba, 2003. 
los apellidos ilustres y se aseguraron posiciones, las cuales se manifestaron por estudiantes y profesionales que se cuestionaron los destinos de la nación desde la legitimidad.

En Cuba, por tanto, la República se cubrió de paradojas al moverse identitariamente entre luces y sombras como todo proceso social. En el camino republicano interactuaron de una parte la corrupción político-administrativa, los fraudes electorales, la dependencia político-económica, pero también transitaron las polémicas culturales de los diversos grupos, instituciones y sus publicaciones periódicas, que crearon y recrearon el itinerario de construcción y deconstrucción de lo cubano, así como se abrieron espacios de visibilidad y ciudadanía desde el contrapunteo de los grupos subalternos con los dispositivos de poder de los grupos hegemónicos. La dinámica establecida en el conglomerado social en esos tiempos reconfiguró toda la plataforma identitaria cultural de la época.

\title{
O IMAGINÁRIO IDENTITÁRIO CUBANO NOS PRIMEROS VINTE ANOS DA REPÚBLICA (1902-1922)
}

\begin{abstract}
RESUMO
O presente artigo se ocupa da construção do imaginário identitário cultural cubano nos primeiros vinte anos da República, desde os diálogos de continuidade e discontinuidade com o período colonial. As polêmicas ou contrapunteos que se produziram em torno ao tema da negritude como chave identitária desde as confluências e interinfluências com o tecido social constituem a agenda temática que tem por objetivo repensar o mistério da identidade cubana na órbita do Caribe.
\end{abstract}

PALAVRAS CHAVE: identidade, contrapunteo, cubano.

Recebido em: 16/03/12

Aprovado em: 25/11/12 